\title{
Adição de farinha de baru em cupcakes: caracterização físico-química e sensorial entre crianças
}

\author{
Baru flour in cupcakes: physico-chemical and sensory
} characterization among children

\author{
Amanda Volz Ortolan* \\ Karolyne Kruger Carvalho Eing* \\ Mirelly Marques Romeiro Santos** \\ Camila Jordão Candido*** \\ Elisvânia Freitas dos Santos**** \\ Daiana Novello****
}

\section{Resumo}

O presente estudo objetivou verificar a aceitabilidade sensorial de cupcakes adicionados de farinha de baru (FB) entre crianças e determinar a composição físico-química da formulação padrão e daquela contendo FB com aceitação sensorial semelhante a padrão. Foram desenvolvidas as seguintes formulações de cupcakes: F1 - 0\% (padrão) e as demais adicionadas de $6 \%$ (F2), 12\% (F3) e 18\% (F4) de FB. Participaram da avaliação sensorial 59 provadores não treinados, de ambos os gêneros, com idade entre 8 e 10 anos. Maiores notas foram verificadas para F1 e F2 comparadas a F4 no atributo aparência. Para as características aroma, sabor, textura, cor, aceitação global e intenção de compra, F1 apresentou maior aceitação que F4, sem diferença entre as demais. Foram verificados maiores teores de umidade, cinzas, proteínas, lipídios, calorias e fibra alimentar em F3 comparado a F1, porém menor teor de carboidratos foi constatado em F3. Assim, a elaboração dos produtos permitiu comprovar que um nível de adição de até $12 \%$ de FB em cupcakes (redução de 50\% de farinha de trigo refinada) foi bem aceito pelos provadores infantis, obtendo-se aceitação sensorial semelhante ao produto padrão e com boas expectativas de comercialização.

Palavras-chave: Cumaru. Castanha. Criança.

\begin{abstract}
The present study aimed to determine the sensory acceptability of cupcakes added baru flour (BF) among children and determine the physico-chemical composition of the standard formulation and that containing BF with similar sensory acceptance standard. The following formulations were developed cupcake: F1 - 0\% (standard) and other added 6\% (F2), 12\% (F3) and 18\% (F4) of BF. Participated in the sensory evaluation 59 untrained, of both genders, aged between 8 and 10 years. Higher scores were observed for F1 and F2, compared to F4 the appearance attribute. For aroma, taste, texture, color, overall acceptance and purchase intent, F1 to F4 showed greater acceptance, with no difference between the others. Higher contents of moisture, ash, protein, lipid, dietary fiber and calories in F3 compared to F1 were checked, but lower carbohydrate content was observed in F3. Thus, the development of products able to prove that an addition level of $12 \%$ BF cupcakes (50\% reduction of refined wheat flour) was well accepted by the children tasters, yielding similar sensory acceptance to the product standard expectations and good marketing.
\end{abstract}

Keywords: Cumaru. Nut. Child.

DOI: $10.15343 / 0104-7809.20164002$

\footnotetext{
* Universidade Estadual do Centro-Oeste, Guarapuava-PR, Brasil. E-mail: av_ortolan@hotmail.com; karolynekruger@hotmail.com

** Universidade Federal de Mato Grosso do Sul, Campo Grande-MS, Brasil. E-mail: mirellymarques@hotmail.com

*** Universidade Federal de Mato Grosso do Sul, Campo Grande-MS, Brasil. E-mail: cahjordao@gmail.com

**** Universidade Federal de Mato Grosso do Sul, Campo Grande-MS, Brasil. E-mail: elisvania@gmail.com

***** Universidade Estadual do Centro-Oeste, Guarapuava-PR, Brasil. E-mail: nutridai@gmail.com

Os autores declaram não haver conflitos de interesse.
} 


\section{INTRODUÇÃO}

O Cerrado brasileiro é composto por diversas plantas nativas, as quais possuem elevado teor nutritivo, grande aceitação sensorial e exploração econômica de baixo custo, ofertando matéria-prima para a formulação de novos produtos alimentícios ${ }^{1}$. Destaca-se aqui o baru (Dipteryx alata vog.), que apresenta elevado potencial econômico e grande aceitabilidade, principalmente em razão de seu sabor agradável².

O baru é classificado como uma semente, sendo considerado como uma leguminosa arbórea de grande porte (15 a 25 metros de altura). Possui alguns nomes populares como cumbaru, cumaru, feijão coco ou emburenabrava. Seu tamanho varia entre 5 e 7 centímetros de comprimento por 3 e 5 centímetros de diâmetro, com peso entre 26 e 40 g. Cada fruto do baru apresenta somente uma semente ${ }^{3}$. Seu perfil nutricional é composto por cálcio, fósforo, manganês ${ }^{4}$, proteínas $(24,57 \%)$, fibras $(17,10 \%)$, carboidratos $(25,8 \%)$, calorias (476 kcal /100 g) 1 e lipídios (40\%), o que se assemelha a composição das nozes ${ }^{5}$. O perfil lipídico do baru apresenta um teor de ácidos graxos saturados e insaturados, que pode variar entre 19,93 a 25,74 g/ $100 \mathrm{~g}, 73,47$ a $79,19 \mathrm{~g} / 100 \mathrm{~g}$, respectivamente. Já a maior concentração em ácidos graxos se refere aos ácidos oleico e linoleico, seguidos pelos ácidos palmítico, lignocérico, esteárico, behênico, gadoleico e araquídico ${ }^{3}$.

Devido ao seu elevado destaque nutricional, o baru tem sido introduzido em diversas formulações alimentícias, substituindo as castanhas tradicionais, inclusive na culinária internacional $^{6}$. Sua utilização na alimentação escolar também vem contribuindo para a redução de carências nutricionais nas crianças, sendo empregado, geralmente, em substituição ao amendoim ${ }^{2}$. Destaca-se que a fase escolar (7 a 10 anos) precede o estirão pubertário, período em que as crianças apresentam maiores necessidades nutricionais. Nesse contexto, um consumo de alimentos com elevados teores de nutrientes pode corrigir possíveis carências nutricionais, colaborando para a redução de doenças crônicas não transmissíveis futuras ${ }^{7}$.
A produção de alimentos panificados vem ganhando grande destaque no mercado brasileiro. Os bolos, por exemplo, elevaram seu consumo e comercialização nos últimos anos, sendo bem aceitos por qualquer faixa etária. Esse fato se deve, em grande parte, às mudanças tecnológicas que possibilitaram a industrialização dos produtos em pequena e grande escala ${ }^{8}$. Assim, devido ao seu elevado consumo e facilidade de preparo e comercialização, os bolos podem ser considerados alimentos em potencial para serem enriquecidos com ingredientes com elevado teor nutricional e/ ou componentes especiais.

Visando o sucesso na elaboração e comercialização de novos alimentos, tornam-se necessárias avaliações periódicas. Dentre elas estão as análises sensoriais e físico-químicas, as quais têm o objetivo de verificar a qualidade e aceitação dos produtos pelos consumidores, bem como potencializar alterações para sua otimização. A análise sensorial, especificamente, avalia a aceitação de várias características do alimento, fato que colabora para a sua aceitabilidade geral. Quando se fala do público infantil, sabe-se que sua opinião é decisiva no momento da compra dos produtos. Nesse aspecto, a indústria alimentícia vem investindo cada vez mais nesse novo nicho do mercado, analisando e valorizando o julgamento das crianças. Assim, técnicas sensoriais voltadas a esta faixa etária são de fundamental importância ${ }^{9,10}$. Diante do exposto, o objetivo deste trabalho foi avaliar a aceitabilidade sensorial de cupcakes adicionados de farinha de baru (FB) entre crianças de idade escolar, bem como determinar a composição físico-química do produto com maior teor de FB e aceitação semelhante ao produto padrão.

\section{MÉTODO}

\section{Aquisição da matéria-prima}

O baru foi adquirido em supermercados da cidade de Mato Grosso do Sul, MS. Os frutos estavam maduros, sendo selecionados aqueles que apresentavam a casca íntegra. Inicialmente, foi realizado um processo de higienização, 
conforme recomendado por Silva Jr. ${ }^{11}$. Cada fruto possuía uma única semente, que foi descascada, manualmente, com auxílio de uma morsa. Posteriormente, as sementes foram torradas em forno convencional (Brastemp ${ }^{\circledR}$, Brasil), à temperatura de $140{ }^{\circ} \mathrm{C}$, durante 30 minutos. Após a torrefação, a casca da semente foi retirada manualmente. Em seguida, as amêndoas foram submetidas ao processo de congelamento em embalagem plástica de polipropileno, em freezer convencional sob temperatura de $-18{ }^{\circ} \mathrm{C}$.

Para obtenção da $\mathrm{FB}$, as sementes foram triturados em liquidificador convencional (Britania $^{\circledR}$, Brasil), por 3 minutos.

\section{Formulações}

Foram elaboradas quatro formulações de cupcakes: $\mathrm{F} 1$ padrão $(0 \%)$ e as demais adicionadas de $6 \%$ (F2), $12 \%$ (F3) e 18\% (F4) de FB. Estes níveis de adição foram definidos através de testes sensoriais preliminares realizados com o produto. Além das porcentagens de FB, os ingredientes utilizados nas formulações foram: farinha de trigo refinada (F1: 24\%, F2: 18\%, F3: $12 \%$ e F4: $6 \%)$, manteiga $(23,79 \%)$, açúcar refinado $(23,62 \%)$, ovos $(23,41 \%)$, fermento químico $(3,84 \%)$ e sal refinado $(1,34 \%)$.

Para a elaboração dos produtos, primeiramente, o açúcar e a manteiga foram batidos em uma batedeira profissional (Kitchen$\operatorname{aid}^{\circledR}$, EUA) e os ovos adicionados um a um até se obter uma massa homogênea. Em seguida, adicionou-se o restante dos ingredientes, que foram misturados manualmente até completa homogeneização (aproximadamente 5 minutos). Com o auxílio de um saco de confeitar a massa foi disposta em forminhas de papel, com $5 \mathrm{~cm}$ de diâmetro, próprias para cupcake. Para garantir uma adequada cocção, os produtos foram dispostos em formas de silicone individuais e, logo após, dispostas em assadeiras de alumínio $(40 \times 30 \mathrm{~cm})$. As formulações foram assadas em forno convencional (Consul ${ }^{\circledR}$, Brasil), pré-aquecido em temperatura média $\left(180{ }^{\circ} \mathrm{C}\right)$ por aproximadamente 12 minutos.

\section{Análise sensorial}

O estudo foi realizado entre os meses de maio e novembro de 2014. Participaram da pesquisa 59 provadores não treinados, sendo crianças devidamente matriculadas em uma Escola Municipal de Guarapuava, PR, de ambos os gêneros e com idade entre 8 e 10 anos.

A análise sensorial foi realizada em uma sala da escola em cabines individuais do tipo urna. Os provadores foram auxiliados pelas pesquisadoras para o preenchimento das respostas. Foram avaliados os atributos de aparência, aroma, sabor, textura e cor. A aceitação das amostras foi analisada através de uma escala hedônica facial estruturada mista de 7 pontos variando de 1 ("Super ruim") a 7 ("Super bom") $)^{12}$. Foram aplicadas também questões de aceitação global e intenção de compra, analisadas através de uma escala estruturada de 5 pontos ( 1 "desgostei muito") "não compraria" a 5 "gostei muito" / "compraria com certeza") $)^{13}$.

Os julgadores receberam uma porção de cada amostra (aproximadamente $10 \mathrm{~g}$ ), em pratos plásticos descartáveis brancos, codificados com números de três dígitos, de forma casualizada e balanceada, acompanhados de um copo de água. As formulações foram oferecidas de forma monádica sequencial.

\section{Índice de aceitabilidade (IA)}

O cálculo do IA das formulações foi realizado segundo a fórmula: $I A(\%)=A \times 100 / B(A=$ nota média obtida para o produto; $B=$ nota máxima dada ao produto $)^{14}$.

\section{Composição físico-química}

As determinações físico-químicas foram realizadas em triplicata na $\mathrm{FB}$, na formulação padrão e naquela com maior teor de FB e com aceitação sensorial semelhante a padrão.

A determinação de umidade foi realizada em estufa $\left(105^{\circ} \mathrm{C}\right)$ até peso constante, enquanto a determinação de cinzas foi realizada em mufla $\left(550{ }^{\circ} \mathrm{C}\right)^{15}$. Para a análise de lipídios totais utilizou-se o método de extração a quente de Soxhlet ${ }^{16}$. As proteínas foram avaliadas por meio do teor de nitrogênio total, utilizandose o método Kjeldahl em nível semimicro ${ }^{15}$ e com fator de conversão de nitrogênio de 6,25. Para avaliação da fibra alimentar foi realizado 
o cálculo teórico das formulações através do programa Avanutri ${ }^{\circledR}$ (Versão 4.5.111) ${ }^{17}$. A determinação de carboidratos dos produtos foi realizada através de cálculo teórico (por diferença) nos resultados das triplicatas, conforme a fórmula: \% Carboidratos $=100$ - (\% umidade $+\%$ proteína $+\%$ lipídios $+\%$ cinzas $+\%$ fibra). O valor calórico total (kcal) foi calculado utilizando os seguintes valores: lipídios (8,37 kcal/ g), proteína $(3,87 \mathrm{kcal} / \mathrm{g})$ e carboidratos $(4,11 \mathrm{kcal} / \mathrm{g})^{18}$.

\section{Determinação do Valor Diário de Referência (VD)}

O VD foi calculado em relação a $40 \mathrm{~g}$ da amostra, com base nos valores médios preconizados para crianças de 8 a 10 anos $^{19}$, resultando em: 2.026,00 kcal/ dia, 276,2 g de carboidratos, 70,80 g/ dia de proteínas, 74,39 g/ dia de lipídios e 13,6 g/ dia de fibra alimentar.

\section{Análise estatística}

Os dados foram analisados com auxílio do software Statgraphics Plus ${ }^{\circledR}$, versão 5.1. Utilizouse a análise de variância (ANOVA), sendo que a comparação de médias foi realizada pelo teste de médias de Tukey e t de student, avaliados com nível de 5\% de significância.

\section{Questões éticas}

Este trabalho foi aprovado pelo Comitê de Ética em Pesquisa da UNICENTRO, parecer número no 608.950/2014. Entretanto, como critérios de exclusão foram considerados os seguintes fatores: possuir alergia a algum ingrediente utilizado na elaboração dos cupcakes, não ser aluno da escola em questão ou não entregar o Termo de Consentimento Livre e Esclarecido (TCLE) assinado pelo responsável legal.

\section{RESULTADOS E DISCUSSÃO}

\section{Análise Sensorial}

Por meio da Tabela 1 verifica-se o resultado da avaliação sensorial dos cupcakes padrão e acrescidos de FB.

Tabela 1- Médias do índice de aceitabilidade (IA) e dos testes sensoriais afetivos e de intenção de compra realizados para as formulações de cupcakes padrão e adicionadas de farinha de baru (FB), Guarapuava, PR, 2014

\begin{tabular}{lcccc}
\hline $\begin{array}{c}\text { Formulações/ } \\
\text { Atributos }\end{array}$ & $\begin{array}{c}\text { F1 } \\
\text { Média } \pm \text { EPM }\end{array}$ & $\begin{array}{c}\text { F2 } \\
\text { Média } \pm \text { EPM }\end{array}$ & $\begin{array}{c}\text { F3 } \\
\text { Média } \pm \text { EPM }\end{array}$ & $\begin{array}{c}\text { F4 } \\
\text { Média } \pm \text { EPM }\end{array}$ \\
\hline Aparência & $5,95 \pm 0,14^{\mathrm{a}}$ & $5,97 \pm 0,15^{\mathrm{a}}$ & $5,46 \pm 0,17^{\mathrm{ab}}$ & $5,25 \pm 0,02^{\mathrm{b}}$ \\
IA (\%) & 85,00 & 85,28 & 78,00 & 75,00 \\
Aroma & $6,02 \pm 0,11^{\mathrm{a}}$ & $5,74 \pm 0,11^{\mathrm{ab}}$ & $5,68 \pm 0,16^{\mathrm{ab}}$ & $5,47 \pm 0,18^{\mathrm{b}}$ \\
IA (\%) & 86,00 & 82,00 & 81,14 & 78,14 \\
Sabor & $6,32 \pm 0,10^{\mathrm{a}}$ & $6,22 \pm 0,12^{\mathrm{ab}}$ & $6,08 \pm 0,13^{\mathrm{ab}}$ & $5,77 \pm 0,16^{\mathrm{b}}$ \\
IA (\%) & 90,28 & 88,86 & 86,86 & 82,43 \\
Textura & $6,36 \pm 0,10^{\mathrm{a}}$ & $6,00 \pm 0,12^{\mathrm{ab}}$ & $5,96 \pm 0,12^{\mathrm{ab}}$ & $5,82 \pm 0,18^{\mathrm{b}}$ \\
IA (\%) & 90,86 & 85,71 & 85,14 & 83,14 \\
Cor & $5,79 \pm 0,10^{\mathrm{a}}$ & $5,42 \pm 0,13^{\mathrm{ab}}$ & $5,51 \pm 0,15^{\mathrm{ab}}$ & $5,16 \pm 0,15^{\mathrm{b}}$ \\
\hline
\end{tabular}




\begin{tabular}{lcccc}
\hline IA (\%) & 82,71 & 77,43 & 78,71 & 73,71 \\
Aceitação global & $4,61 \pm 0,07^{\mathrm{a}}$ & $4,48 \pm 0,08^{\mathrm{ab}}$ & $4,49 \pm 0,08^{\mathrm{ab}}$ & $4,21 \pm 0,13^{\mathrm{b}}$ \\
IA (\%) & 92,20 & 89,60 & 89,80 & 84,20 \\
Intenção de compra & $4,68 \pm 0,06^{\mathrm{a}}$ & $4,35 \pm 0,11^{\mathrm{ab}}$ & $4,41 \pm 0,11^{\mathrm{ab}}$ & $4,27 \pm 0,11^{\mathrm{b}}$ \\
\hline
\end{tabular}

* Letras diferentes na linha indicam diferença significativa pelo teste de Tukey $(p<0,05)$; EPM: erro padrão da média; F1: padrão (0\%); F2: 6\% de FB; F3: 12\% de FB; F4: 18\% de FB.

Para o atributo aparência, maiores notas foram verificadas para as formulações F1 e F2, comparadas a F4, sem diferença estatística de F3. Já para os atributos aroma, sabor, textura, cor, aceitação global e intenção de compra, F1 apresentou maior aceitação que F4, sem diferença entre as demais. Assim, verifica-se que conforme se aumentou os teores de FB houve uma redução na preferência dos cupcakes. Resultados semelhantes para os atributos aparência, sabor e textura foram verificados por Soares Junior, et $\mathrm{al}^{2}$ que avaliaram biscoitos contendo FB (2, 4, 6 e 8\%).

$A$ adição de $\mathrm{FB}$ promoveu uma coloração mais escura aos cupcakes. Esse fato pode ser
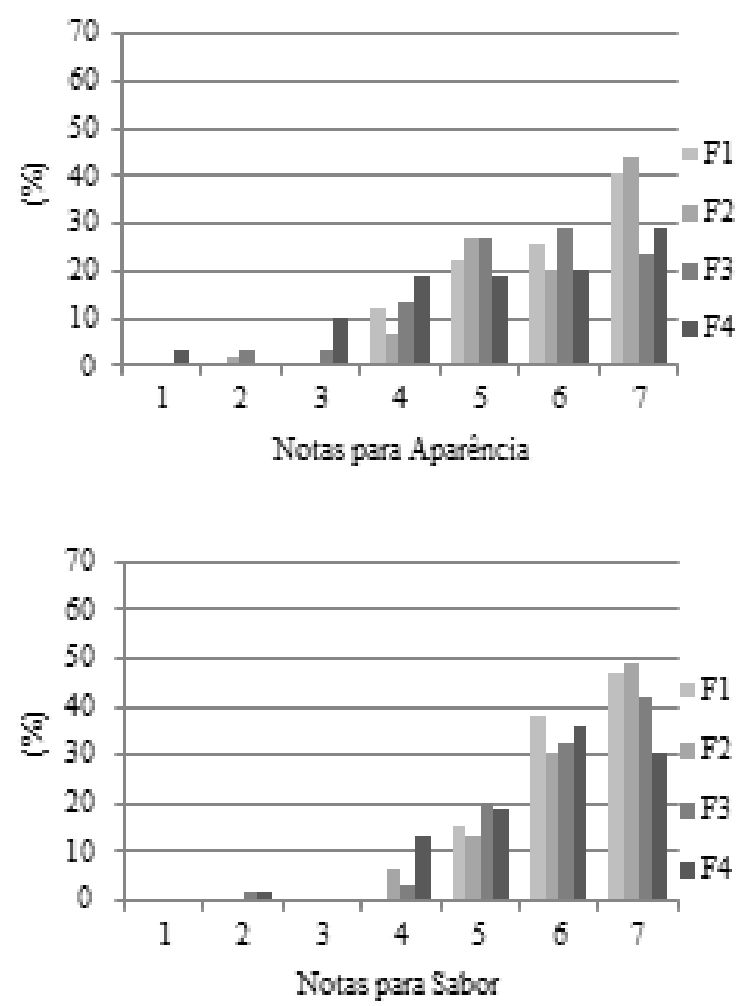

explicado pelo elevado teor de fibra presente no baru, o que causa um escurecimento no produto $^{2}$. Outras mudanças observadas foram quanto à textura e o rendimento da preparação. Maiores quantidades de FB aumentaram a umidade e a rigidez dos produtos. Segundo Lemos, et $\mathrm{al}^{20}$, isso ocorre devido à grande quantidade de óleo presente no baru, que pode variar entre 35 e 43\%. Entretanto, todas as formulações apresentaram IA acima de $70 \%$, o qual as classifica os cupcakes com boa aceitação sensorial ${ }^{21}$.

A Figura 1 apresenta a distribuição dos provadores pelos valores hedônicos para cada atributo sensorial.
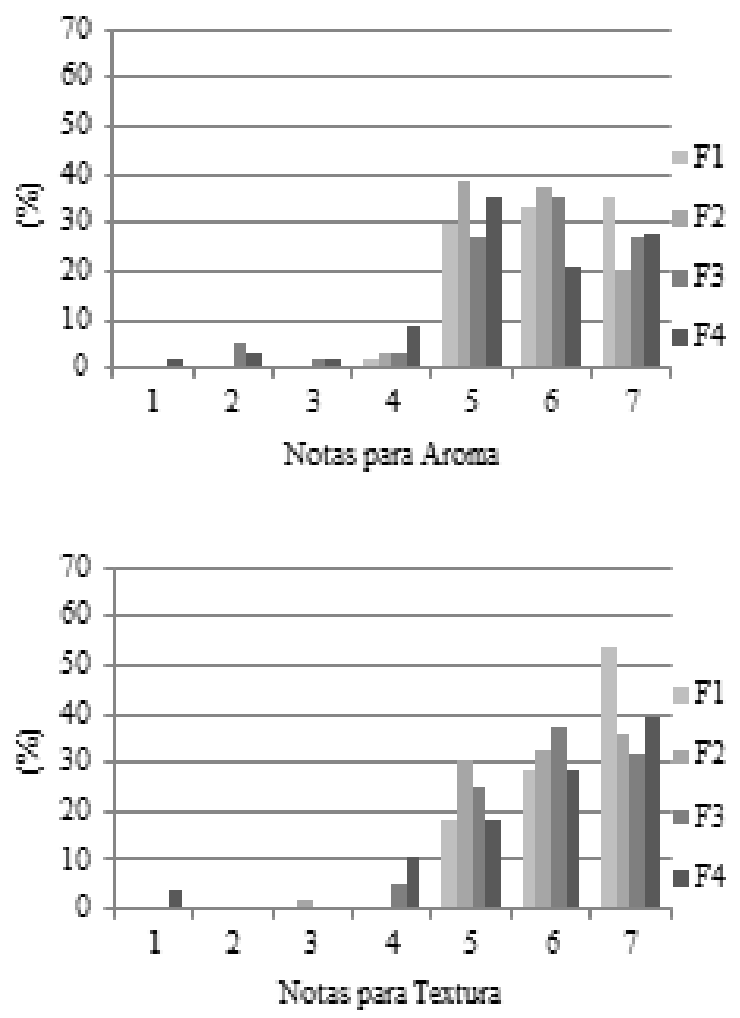

continua.. 

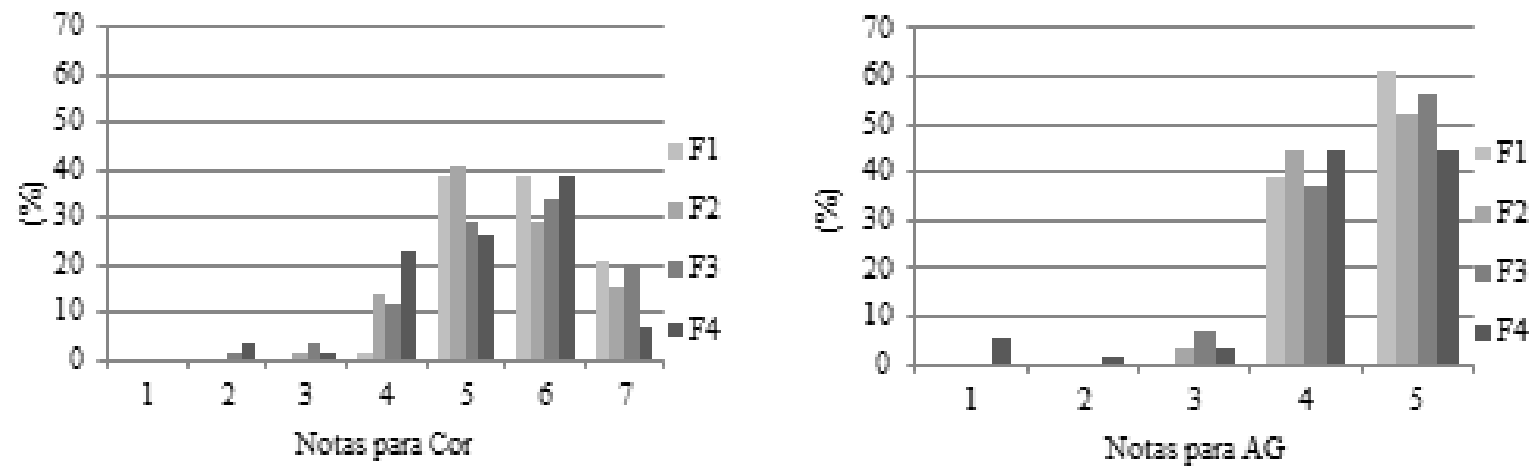

Figura 1- Distribuição dos provadores pelos valores hedônicos obtidos na avaliação dos atributos aparência, aroma, sabor, textura, cor e aceitação global dos cupcakes padrão (F1) e adicionados de 6,0\% (F2), 12,0\% (F3) e 18,0\% (F4) de farinha de baru, Guarapuava, PR, 2014

As notas para todos os atributos e formulações se concentraram acima de 5 ("bom"). Contudo, na aceitação global as notas mais citadas foram 4 ("gostei") e 5 ("gostei muito"). Resultados similares foram relatados por Lima, et $\mathrm{al}^{22}$, que avaliaram barras de cereal contendo FB (5 e 10\%). Segundo Zambiazi, et $\mathrm{al}^{23}$, quanto maior a adição de FB maior o sabor residual no produto, fato que explica a menor aceitação de F4.

A amostra F3 (12,0\%) foi selecionada para fins de comparação com à padrão (F1) por ser aquela com o maior teor de FB e com aceitação semelhante ao produto padrão em todos os quesitos avaliados.

\section{Composição físico-química}

Por meio da Tabela 2 observa-se os valores da composição físico-química dos cupcakes padrão e com $12 \%$ de FB, comparados a um produto referência.

Em estudos de Lima, et $\mathrm{al}^{22}$, verificou-se para a FB maiores teores de cinzas $(3,03 \%)$ e proteínas $(26,97 \%)$ e menores conteúdos de umidade $(3,23 \%)$, lipídios $(40,98 \%)$, carboidratos $(11,53 \%)$, fibras $(14,26 \%)$ e calorias $(522,82 \%)$ que os verificados no presente estudo. Essas variações podem ser explicadas devido à distintos fatores que podem influenciar os frutos, como, por exemplo, a genética, condições climáticas, recomposição das formações naturais e o manejo pós-colheita do fruto ${ }^{3}$.

Maiores teores de umidade, cinzas, proteínas, lipídios e calorias foram constatados em F3 comparando-se a F1 $(p<0,05)$, entretanto F3 apresentou menores conteúdos de carboidratos $(p<0,05)$, corroborando com Lima, et $\mathrm{al}^{22}$. O aumento no conteúdo nutricional verificado em F3 pode ser explicado devido aos elevados teores desses nutrientes presentes no baru, quando comparado a farinha de trigo (cinzas: 0,8 g/ $100 \mathrm{~g}$, proteínas: 9,8 g/ 100 g, lipídios: 1,4 g / 100 g e calorias: 360 kcal/ 100 g) 24. Já a redução de carboidratos ocorreu, pois a farinha de trigo possui maior teor desse nutriente $(75,1$ g/ 100 g) em sua composição, comparada ao baru $^{24}$.

Apesar de ter havido um aumento na quantidade de lipídios dos cupcakes contendo $\mathrm{FB}$, deve-se ressaltar que este ingrediente possui alto teor de ácidos graxos n-6 (25,51 g/ $100 \mathrm{~g})$ e n-9 $(47,15 \mathrm{~g} / 100 \mathrm{~g})^{3}$. Estas substâncias são consideradas funcionais e benéficas à saúde, pois auxiliam na modulação da resposta inflamatória e imunológica, além de desempenhar papel na agregação plaquetária, crescimento e diferenciação celular ${ }^{25}$. Calculando-se o teor médio teórico de n-6 e n-9 das amostras F1 e F3 verifica-se um total de 0,03 g/ 100 g de n-6 e 0,07 g/ 100 g de n-9 e 0,56 g/ $100 \mathrm{~g}$ de n-6 e 3,78 g/ 100 g de n-9, respectivamente ${ }^{3}$, sendo possível um aumento de $1,77 \%$ (n-6) e 5,20\% 
(n-9) em F3, comparado ao produto padrão.

Ressalta-se que, recentemente, a literatura científica demonstrou que o consumo de baru pode promover também uma proteção contra o estresse oxidativo, fato que se deve à presença de compostos bioativos como os tocoferóis ácido fítico e taninos no fruto ${ }^{26}$.

Um dos principais resultados deste trabalho foi o teor de fibras verificado na formulação com adição de FB (1,88 g/ 100 g-1 ${ }^{1}$ ), expressando um aumento significativo de $242 \%$ em relação a
F1. Isso se deve, principalmente, ao alto teor de fibras presente no baru, efeito confirmado por Lima, et $\mathrm{al}^{22}$.

Os resultados verificados na presente pesquisa tornam os cupcakes uma boa fonte de fibras para a faixa etária em questão, visto que as crianças apresentam um consumo de fibras abaixo do recomendado $(6,91 \mathrm{~g}$ para meninos e 6,52 g para meninas) ${ }^{27}$, considerando-se como recomendação ideal um valor de 13,7 g para os meninos e 12,6 g para as meninas ${ }^{19}$.

Tabela 2- Composição físico-química e valores diários recomendados - VD* (porção média de 40 gramas - 1 unidade) do cupcake padrão (F1) e daquele adicionado de $12 \%$ de farinha de baru (F3), comparados à um produto referência**, Guarapuava, PR, 2014

\begin{tabular}{|c|c|c|c|c|c|c|}
\hline \multirow[b]{2}{*}{ Avaliação } & \multirow{2}{*}{$\begin{array}{l}\begin{array}{l}\text { Farinha } \\
\text { de baru }\end{array} \\
\text { Média } \pm D P\end{array}$} & \multicolumn{2}{|l|}{ F1 } & \multicolumn{2}{|l|}{ F3 } & \multirow[t]{2}{*}{ 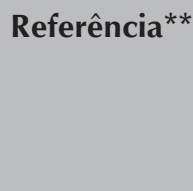 } \\
\hline & & Média $\pm D P$ & VD $(\%)^{*}$ & Média $\pm D P$ & $\operatorname{VD}(\%)^{*}$ & \\
\hline Umidade (\%) & $4,02 \pm 0,01$ & $19,86 \pm 0,01^{b}$ & ND & $20,05 \pm 0,02^{\mathrm{a}}$ & ND & ND \\
\hline Cinzas (g.100g-1)*** & $2,94 \pm 0,01$ & $0,77 \pm 0,02^{b}$ & ND & $1,38 \pm 0,01^{\mathrm{a}}$ & ND & ND \\
\hline Proteínas (g.100g-1)*** & $21,17 \pm 0,08$ & $5,02 \pm 0,09^{b}$ & 2,83 & $6,53 \pm 0,05^{\mathrm{a}}$ & 3,69 & 2,20 \\
\hline Lipídios (g.100g-1)*** & $42,49 \pm 0,09$ & $23,40 \pm 0,06^{b}$ & 12,58 & $27,65 \pm 0,06^{a}$ & 14,87 & 6,40 \\
\hline $\begin{array}{l}\text { Carboidratos } \\
(\text { g. } 100 \mathrm{~g}-1)^{\star * *}\end{array}$ & $29,38 \pm 0,58$ & $50,95 \pm 0,47^{\mathrm{a}}$ & 7,38 & $44,39 \pm 0,31^{b}$ & 6,43 & 20,00 \\
\hline Calorias (kcal.100g-1)*** & $558,33 \pm 0,87$ & $424,70 \pm 0,96^{b}$ & 8,38 & $439,12 \pm 0,74^{\mathrm{a}}$ & 8,67 & 146,00 \\
\hline $\begin{array}{l}\text { Fibra } \\
\text { alimentar (g.100g-1)**** }\end{array}$ & 15,72 & 0,55 & 1,62 & 1,88 & 5,53 & 0,60 \\
\hline
\end{tabular}

Letras diferentes na linha indicam diferença significativa pelo teste de t de student $(p<0,05)$; $V D$ : nutrientes avaliados pela média da National Research Council ${ }^{19}$, com base numa dieta de $2.026,00 \mathrm{kcal} / \mathrm{dia}$; ${ }^{* *}$ Valores comparados com produto comercial, marca líder de mercado; ${ }^{* * *}$ Valores calculados em base úmida; ${ }^{* * *}$ Cálculo teórico; DP: desvio padrão da média; ND: não disponível.

\section{CONCLUSÃO}

Conclui-se que um nível de adição de até $12 \%$ de farinha de baru em cupcakes (redução de $50 \%$ de farinha de trigo refinada) é bem aceito pelos provadores infantis, obtendo-se aceitação sensorial semelhante ao produto padrão e altos índices de aceitabilidade. Entretanto, maiores concentrações de farinha de baru reduzem a preferência dos produtos.

A adição de $12 \%$ de farinha de baru em cupcakes aumenta os teores de umidade, cinzas, proteínas, lipídios, calorias e fibra alimentar, contudo diminui o conteúdo de carboidratos dos produtos. Assim sendo, o baru pode ser considerado um potencial ingrediente para adição em bolos e similares, podendo ser oferecidos aos consumidores infantis com altas expectativas de aceitação no mercado. 


\section{REFERÊNCIAS}

1. Rocha LS, Santiago RAC. Implicações nutricionais e sensoriais da polpa e casca de baru (Dipterix Alata vog.) na elaboração de pães. Ciên Tecnol Alim.2009; 29(4):820-825.

2. Soares Júnior MS, Caliari M, Torres MCL, Vera R, Teixeira JS, Alves LC. Qualidade de biscoitos formulados com diferentes teores de farinha de amêndoa de baru (dipteryx alata vog.). Pesq Agropec Trop.2007; 37(1):51-56.

3. Vera R, Soares Junior MS, Naves RV, Souza ERB, Fernandes EP, Caliari M, Leandro WM. Características químicas de amêndoas de barueiros (Dipteryx alata Vog.) de ocorrência natural no cerrado do estado de Goiás, Brasil. Rev Bras Frut.2009; 31(1):112-118.

4. Fernandes DC, Freitas JB, Czeder LP, Naves MMV. Nutritional composition and protein value of the baru (Dipteryx alata Vog.) almond from the Brazilian Savanna. J Sci Food Agric.2010; 90(10):1650-1655.

5. Freitas JB, Naves MMV. Composição química de nozes e sementes comestíveis e sua relação com a nutrição e saúde. Rev Nutr.2010; 23(2):269-279.

6. Pineli LLO, Carvalho MV, Aguiar LA, Oliveira GT, Celestino SMC, Botelho RBA, Chiarello MD. Use of baru (Brazilian almond) waste from physical extraction of oil to produce flour and cookies LWT - Food Sci Technol. 2015; 60(1):50-55.

7. Bertin RL, Malkowski J, Zutter LCl, Ulbrich AZ. Estado nutricional, hábitos alimentares e conhecimentos de nutrição em escolares. Rev Paul Ped.2010; 28(3):303-308.

8. Zavareze ER, Moraes KS, Salas-Mellado MLM. Qualidade tecnológica e sensorial de bolos elaborados com soro de leite. Ciên Tecnol Alim.2010; 30(1):1-6.

9. Dutcosky SD. Análise Sensorial de Alimentos. $4^{\underline{a}}$ ed Curitiba (PR): Champagnat; 2014.

10. Domene SMÁ, Veiga FM, Marino CRP, Assumpção ALM, Zabotto CB, Vitolo MR. Validação de metodologia para análise sensorial com pré-escolares. Rev Ciên Méd.2012; 11(2):129-136.

11. Silva Júnior EA. Manual de Controle Higiênico - Sanitário Em Serviços de Alimentação. 7 ed. São Paulo (SP): Varella; 2014.

12. Resurreccion AVA. Consumer Sensory Testing for Product Development. Gaithersburg (MD): Aspen Publishers; 1998.

13. Minim VPR. Análise Sensorial: estudo com consumidores. 3a ed. Viçosa (MG): UFV; 2013.

14. Monteiro CLB. Técnicas de avaliação sensorial. Curitiba (PR): Centro de Pesquisa e processamento de Alimentos; 1984.

15. Horwitz W, Latimer Jr GW, editors. Official methods of analysis of AOAC International. 18a ed. Gaithersburg (MD): AOAC International; 2011.

16. Brasil. Ministério da Saúde. Agência Nacional de Vigilância Sanitária. Métodos físico-químicos para análise de alimentos. 4 ed. Brasilia (DF): Ministério da Saúde; 2005.

17. Avanutri. Avanutri eficácia em nutrição. 2012 [acesso 23 Mai 2016]. Disponível em: http://www.avanutri.com.br/.

18. Merrill AL, Watt BK. Energy values of foods: basis and derivation. Washington (DC): USDA; 1973.

19. National Research Council. Dietary reference intakes for energy, carbohydrate, fiber, fat, fatty acids, cholesterol, protein and amino acids (macronutrients). Washington (DC): National Academy Press; 2005.

20. Lemos MR, Siqueira E, Zambiazi RC, Rutz JK, Voss GB. Composição do teor de lipídeos da amêndoa de baru (Dipteryx alataVog.), antes e após tratamento térmico. In: Encontro de Pós-Graduação (ENPOS), 13., 2011, Pelotas. Anais... Congresso de Iniciação Científica da Universidade Federal de Pelotas; 2011. p.1-4.

21. Teixeira E, Meinert E, Barbetta PA. Análise sensorial dos Alimentos. Florianópolis (SC): UFSC; 1987.

22. Lima JCR, Freitas JB, Czeder LP, Fernandes DC, Naves MMV. Qualidade microbiológica, aceitabilidade e valor nutricional de barras de cereais formuladas com polpa e amêndoa de baru. Bol CEPPA.2010; 28(2):331-343.

23. Zambiazi RC, Przybylsk RI, Zambiazi MW, Mendonça CRB. Fatty acid composition of vegetable oils and fats. Bol CEPPA.2007; 25(1):111-120.

24. Universidade Estadual de Campinas - UNICAMP. Tabela brasileira de composição de alimentos - TACO. 4a ed. Campinas (SP): NEPA/UNICAMP; 2011.

25. Soares LA, Takeuti TD, Valeri PAO, Silva AA, Lara BHJ, Terra-Júnior JA, Freitas O, Crema E. Impactos nutricionais da ingestão alimentar dos ácidos graxos ômega 3 e óleo de palma: uma revisão. RBONE.2016; 10(56):105-114.

26. Siqueira EMA, Marin AMF, Arruda SF, Cunha MSB, Fustinoni AM, Dourado LP. Consumption of baru seeds [Dipteryx alata Vog.], a Brazilian savanna nut, prevents iron-induced oxidative stress in rats. Food Res Intern.2012. 45(1)427-433.

27. Mello CS, Freitas KDC, Tahan S, Morais MBD. Consumo de fibra alimentar por crianças e adolescentes com constipação crônica: influência da mãe ou cuidadora e relação com excesso de peso. Rev Paul Ped.2010; 28(2):188-193.

Recebido em 19 de fevereiro de 2015. Aprovado em 27 de março de 2016. 